\title{
Extinction performance as a function of $R-R$ transitions with abbreviated training '
}

JAMES E. SPIVEY, DAVID T. HESS AND JOSEPH F. APONTE UNIVERSITY OF KENTUCKY

Resistance to extinction for albino rats given abbreviated training in a runway was an increasing function of number of $R-R$ transitions. The results were interpreted as supporting the modified aftereffects hypothesis.

Recent research employing albino rats in instrumental reward learning situations indicates that extinction performance following partial reinforcement training is more a function of differential conditioning of the aftereffect $(\mathrm{s})$ of nonreinforcement $\left(\mathrm{S}^{\mathrm{N}}\right)$ than of certain gross variables such as reinforcement percentage and number of reinforced (R) or nonreinforced (N) trials. This finding, which particularly presents difficulties for the frustration position (Amsel, 1958), is in accord with the modifled aftereffects hypothesis (Capaldi, 1964; Capaldi \& Hart, 1962; Capaldi \& Spivey, 1963).

Following the assumptions (1) that an $\mathrm{N}$ trial generates a distinctive stimulus, $\mathrm{S}^{\mathrm{N}},(2)$ that in acquisition N-R trial sequences (transitions) present an opportunity for the conditioning of $\mathrm{SN}^{\mathrm{N}}$ to the to-be-learned response, (3) that in extinction $\mathrm{SN}^{\mathrm{N}}$ will be a dominant part of the stimulus complex on every trial after the first trial, and (4) that extinction performance will be a function of the strength of conditioning of the learned response to $\mathbf{S N}$, the major variables with which those investigators working within the framework of the aftereffects hypothesis have been concerned are those associated with $\mathrm{SN}^{2} 2$

However, an $R$ trial is also assumed to result in a distinctive stimulus, $S R$, which is assumed to be present and available for conditioning on the subsequent trial. Therefore, with increasing numbers of R-R transitions, $\mathrm{SR}$ should become more strongly conditioned to the instrumental response. Further, if $\mathrm{SN}^{\mathrm{N}}$ and $\mathrm{S}^{\mathrm{R}}$ contain common or similar elements, then through stimulus generalization a response conditioned to $\mathbf{S} \mathbf{R}$ should be evoked by $\mathrm{SN}$, and resistance to extinction should be an increasing function of number of $R-R$ transitions. The present study constituted a test of this deduction. Method

The 28 Ss were experimentally naive, 90 day old male albino rats of the Sprague-Dawley strain, supplled by the Holtzman Co., of Madison, Wis. Fourteen Ss were randomly assigned to each of two groups. Throughout the experiment Ss were maintained on a $23 \mathrm{~h}$ food deprivation schedule consisting of a $1 \mathrm{~h}$ ad $\mathrm{lib}$ feeding of wet mash beginning $15 \mathrm{~min}$ after the end of each day's training; water was continuously available in the home cage.

The apparatus was a wire-covered plywood runway, 75 in. long $\times 4$ in. wide $\times 9$ in. deep, the initial 60 in. midgray portion of which was separated from the 15 in. flat black goal box (GB) by an aluminum gullotine-type door which was used to prevent retracing. The GB housed a two compartment aluminum food cup which could be slid perpendicular to the alley sothat only one compartment was in the GB at a time. Each compartment measured 2 in. from front to back, $4 \mathrm{in}$, in width, and 1-1/2 in. in depth. Running times over a 60 in. distance were computed by summing the alley and goal section times, which were recorded on Standard Electric timers connected to a $10 \mathrm{in.} \mathrm{floor} \mathrm{treadle} \mathrm{and} \mathrm{two}$ photocells located $48 \mathrm{ln}$. and $60 \mathrm{in}$. beyond the treadle. When $\mathrm{S}$ passed the last photobeam, located 3 in. in front of the food cup, the tight-fitting cup lid was pulled through the rear of the GB by a small noiseless motor. The retraction of the lid was silent and was of sufficient speed to insure that the compartment was immediately avallable upon the arrival of $S$ at the food cup.

After nine days on the deprivation schedule, each $S$ was handled individually for $15 \mathrm{~min}$ per day for five days on a 36 in. sq aluminum pan with wet mash avallable. On Day 15, each $S$ was gdven two 2 min $R$ placements in the GB, each of which was followed by a $1 \mathrm{~min}$ confinement in the 12 in. sq $\times 24$ in. deep unpainted intertrial interval (ITI) box. On Day 16, four $1 \mathrm{~min} R$ placements were given and the ITI was 30 sec. On the last three placements of Day 16, the food cup lid was closed, $S$ was placed at the front of the GB, and the lid retracted as $S$ advanced through the photobeam. Beginning on Day 15, Immediately upon entering the experimental room, $\mathbf{S}$ was placed in the ITI box for the period of time called for on that day for the IM. On Days 17 and 18, each $S$ was given one $R$ trial in the alley; both GB and ITI box confinement curations were $30 \mathrm{sec}$. Beginning on Day 17, If S did not complete a section of the alley within $60 \mathrm{sec}, \mathrm{S}$ was gently forced into the GB and 60 sec was recorded for each uncompleted sectlon.

On each of the three days of acquisition, Days 19-21, one $N$ and three $R$ trials were given, each of which terminated in a $15 \mathrm{sec}$ confinement in the GB followed by a $15 \mathrm{sec} I T I$. On $R$ trials $S$ was confined with wet mash avallable; on $N$ trials $S$ was confined with the exposed empty food compartment, with wet mash present, but not visible, in the adjoining compartment. The reinforcement patterns for Group $3 R-R$ and Group 6 R-R each day were RNRR and NRRR, respectively. Note that each schedule contains one $\mathrm{N}-\mathrm{R}$ transition of $\mathrm{N}$-length $\mathrm{N}_{1}$, but involves elther one or two dally $R-R$ transitions for a total of elther three or six R-R transitions in acquisition.

Extinction tralning consisted of five $\mathrm{N}$ trials per day 


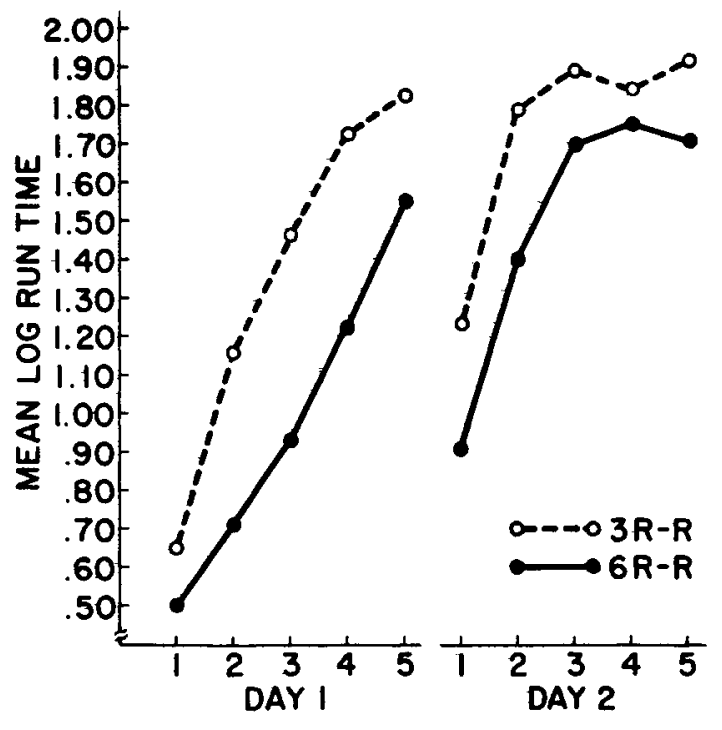

Fig. 1. Mean log running time across extinction trials.

for Days 22 and 23. The only procedural change effected in extinction was the absence of mash in the adjoining food compartment.

Results

The group mean log running times in extinction are presented in Fig. 1. All analyses were performed on the logarithms of the individual $S$ running times in extinction. Analyses of variance indicated that the two groups did not differ either on the initial trial of acquisition $(F<1)$, or on Trial 1 of extinction $(F=1.45$, $d f=1 / 26, p>.10)$. A repeated measures analysis of variance applied to the log running times on Day 1 of extinction indicated that the group that had received six $R-R$ transitions ran signiflcantly faster $(F=13.70, d f=1 / 26$, $p<.005)$ and extinguished at a slower rate $(F=2.58$, $\mathrm{df}=4 / 104, \mathrm{p}<.05$ ) than the group that had received only three R-R transitions. On Day 2 of extinction the group that had received the greater number of $R-R$ transitions continued to be the faster running group $(F=6.93, d f=$ $1 / 26, p<.025$ ).

Discussion

The finding in the present investigation that resistance to extinction following abbreviated training is an increasing function of number of $R-R$ transitions is interpreted as adding further support to the modified aftereffects hypothesis. This result is consistent with the findings of several other studies involving abbreviated training in arguing that predictions concerning extinction performance must take into account sequential variables which are a function of the specific partial reinforcement patterns employed (Capaldi \& Hart,1962; Capaldi, Hart, \& Stanley, 1963; Capaldi \& Spivey, 1963, 1964; Capaldi \& Wargo, 1963; McCain, 1966; Spivey, in press; Spivey \& Hess, 1967). In view of the small number of training trials involved, these studies suggest that the frustration hypothesis (Amsel, 1958) and the various discrimination hypotheses (e.g., Gonzalez \& Bitterman, 1964) are at least inadequate.

On the basis of the growing body of evidence supporting the modified aftereffects hypothesis, the so called partial reinforcement effect is viewed as a design artifact, and extinction performance is seen as a special case of transfer of training. More specifically, in extinction $\mathrm{SN}^{\mathrm{N}}$ will be present on every trial after the first trial and extinction performance will be a function of the strength of association of $\mathrm{S}^{\mathrm{N}}$ with the instrumental response, whether this association develops through direct conditioning of $\mathrm{S}^{\mathrm{N}}$ or through stimulus generalization.

\section{References}

AMSEL, A. The role of frustrative nonreward in non-continuous reward situations. Psychol Bull., 1958, 55, 102-119.

CAPALDI, E. J. Effect of N-length, number of different N-lengths, and number of reinforcements on resistance to extinction. J. exp. Psychol, $1964,68,230-239$.

CAPALDI, E. J., \& HART, D. Influence of a small number of partial reinforcement training trials on resistance to extinction. J. exp. Psychol, $1962,64,166-171$.

CAPALDI, E. J., HART, D., \& STANLEY, L. R. Effect of intertrial reinforcement on the aftereffect of nonreinforcement and resistance to extinction. J. exp. Psychol, 1963, 65, $70-74$.

CAPALDI, E. J., \& SPIVEY, J. E. Effect of goal-box similarity on the aftereffect of nonreinforcement and resistance to extinction. $J$. exp. Psychol, 1963, 66, 461-465.

CAPALDI, E. J,, \& SPIVEY, J. E. Intertrial reinforcement and aftereffects at 24-hour intervals. Psychon. Sci, 1964, 1, 181-182.

CAPALDI, E. J., \& WARGO, P. Effect of transitions from nonreinforced to reinforced trials under spaced-trial conditions. J. exp. Psychol, 1963, 65, 318-319.

GONZALEZ, R. C., \& BITTERMAN, M. E. Resistance to extinction in the rat as a function of percentage and distribution of reinforcement. J. comp. physiol Psychol, 1964, 58, 258-263.

McCAIN, G. Partial reinforcement effects following a small number of acquisition trials. Psychon Monogr. Suppl, 1966, 1, 251-270.

SPIVEY, J. E. Resistance to extinction as a function of number of N-R transitions and percentage of reinforcement. J. exp. Psychol., 1967, in press.

SPIVEY, J. E., \& HESS, D. T. Modification of reinforcement aftereffects and level of training. Paper read at Southeast. Psychol. Assoc. Conv., Atlanta, 1967.

\section{Notes}

1. This research was supported by NIMH Grant MH 13371-01, by research grants from the University of Kentucky Research Committee, and by a University of Kentucky Summer Faculty Research Fellowship, each to the first author. An earlier version of this paper was presented by the first two authors at the SEPA convention held in Atlanta in April, 1967. $2 . \mathrm{S}^{\mathrm{N}}$ is used herein to represent a class of stimuli. For a discussion of some of the members of this class, referred to as $\mathrm{N}$-length variables, see Capaldi (1964). 